\title{
Granuloma annulare treated with narrowband UVB phototherapy*
}

\author{
Bianca Pinheiro Bousquet Muylaert ${ }^{1}$ \\ Rossana Cantanhede Farias de Vasconcelos ${ }^{1}$
}

\author{
Roberta Almada ${ }^{2}$
}

DOI: http:/ /dx.doi.org/10.1590/abd1806-4841.20174994

\begin{abstract}
Granuloma annulare is a benign cutaneous inflammatory disease, whose lesions have spontaneous improvement in two years in $50 \%$ of cases, but there is recurrence in $40 \%$ of patients. Treatment may be topical, intralesional or systemic. The use of phototherapy with narrowband UVB is highlighted, whose mechanism of action in this disease is still unclear, probably related to the inhibition of $\mathrm{T}$ lymphocytes. Herein, a case of a disseminated granuloma annulare of difficult therapeutic management is described. It was treated with narrowband UVB phototherapy twice a week for six months, with good clinical improvement, being a good low-risk therapeutic option and that, in this case, provided quick and satisfactory response.
\end{abstract}

Keywords: Phototherapy; Granuloma annulare; Ultraviolet therapy

\section{INTRODUCTION}

Granuloma annulare (GA) is a benign inflammatory skin condition that classically presents as non-itchy, coalescent annular plaques, usually located on the dorsum of the hands. ${ }^{1}$ It occurs in all age groups, and is rare in childhood. There are the localized and subcutaneous types (that usually affect children and young adults), the disseminated type (more common in female adults), and the perforating and macular types. ${ }^{2,3}$ The histology is characterized by complete or incomplete collagen necrobiosis, associated to an inflammatory infiltrate represented by macrophages in particular, that are placed in between and around degenerated collagen fibers. ${ }^{2}$ The lesions resolve spontaneously in two years in $50 \%$ of the cases. However, $40 \%$ of patients recur and the condition can also persist for years, causing an impact in the patient's quality of life. ${ }^{3}$

We present a case of disseminated GA with difficult management.

\section{CASE REPORT}

Sixty-one-year-old female patient had asymptomatic lesions on the back, that spread to the chest and upper limbs two months before the first consultation. She had diabetes mellitus, for which she used metformin; hypothyroidism, for which she used levothyroxine; dyslipidemia, for which she used simvastatin; and had donated a kidney 26 years back.

On dermatological examination, there were erythematous, confluent papules in an annular pattern, with centrifugal spread and normochromic center on the back, chest and upper limbs (Figures 1 to 3). The differential diagnoses were erythema annulare centrifugum and granuloma annulare.

A biopsy was done on the chest and the histology showed superficial interstitial granulomatous dermatitis with mild mucinosis. It was suggestive of interstitial GA.

Sulfone treatment was commenced at $100 \mathrm{mg} /$ day and discontinued after three days due to hematuria. She was then treated with intramuscular betamethasone, clobetasol cream under occlusion and cryotherapy, with no significant improvement of the lesions.

We opted to prescribe narrowband UVB phototherapy twice a week for six months, with 48 sessions in total and cumulative dose of $13,440 \mathrm{~J} / \mathrm{cm}^{2}$. She showed response after the third week,

\footnotetext{
Study submitted on 02.08 .2015

Approved by the Advisory Board and accepted for publication on 24.04.2016

- Study conducted at Universidade de Santo Amaro (UNISA) - Santo Amaro (SP), Brazil.

Financial Support: None.

Conflict of Interests: None.

Department of Dermatology of the Universidade de Santo Amaro (UNISA) - Santo Amaro (SP), Brazil.

2 Private practice - São Paulo (SP), Brazil.
} 


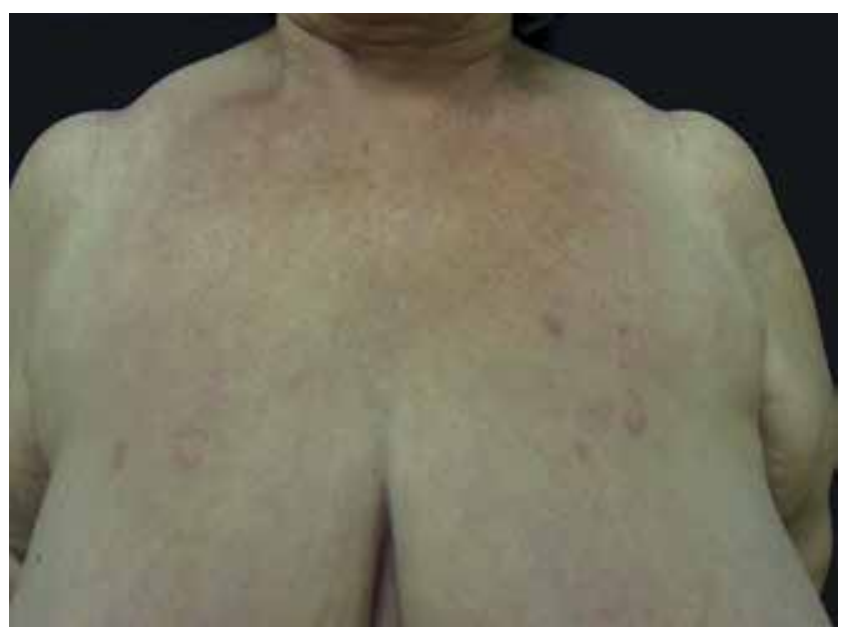

FIGURE 1: Erythematous plaques with an annular configuration on the chest

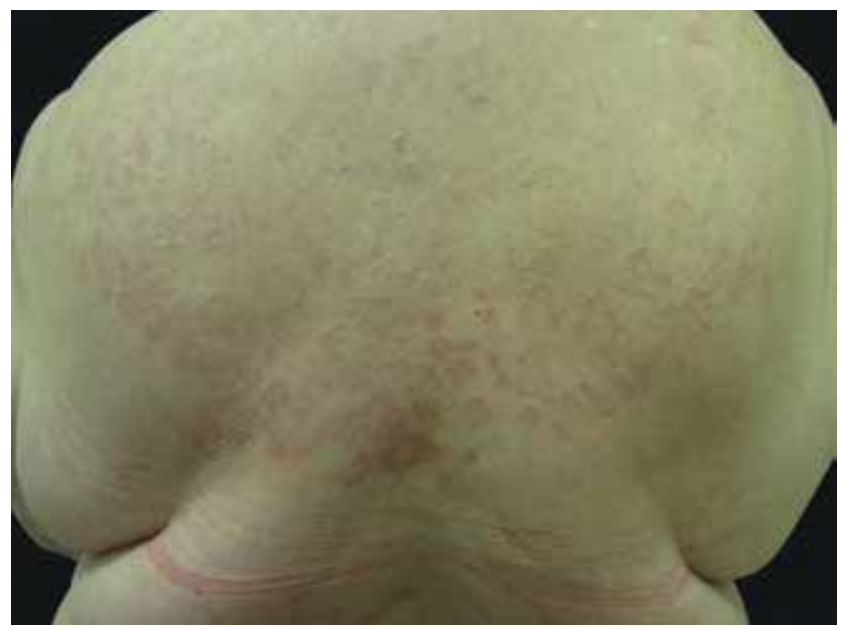

FIGURE 2: Erythematous plaques with an annular configuration on the back

with good tolerance to the treatment and complete resolution of the lesions in the end. Two years after finishing the treatment, the patient is still undergoing follow up every six months, with no recurrence and is in use of moisturizers only (Figure 4).

\section{DISCUSSION}

Disseminated GA presents as disseminated papules, some of which coalesce to form small annular plaques or large discolored patches, with raised, arcuate and serpiginous margins. Face and genital area are usually spared. ${ }^{4}$ This type is responsible for 8 to $15 \%$ of the cases, especially in female adult patients and is strongly linked to hypercholesterolemia. ${ }^{3}$

GA is associated with diabetes mellitus, thyroid diseases, dyslipidemia, rheumatoid arthritis and malignancies, such as lymphomas. ${ }^{5}$ Its etiology is unknown and the pathogenesis poorly understood, being also associated with insect bites, minor trauma, HIV infection, tuberculin test, sun exposure, viral infections, among others. ${ }^{2}$

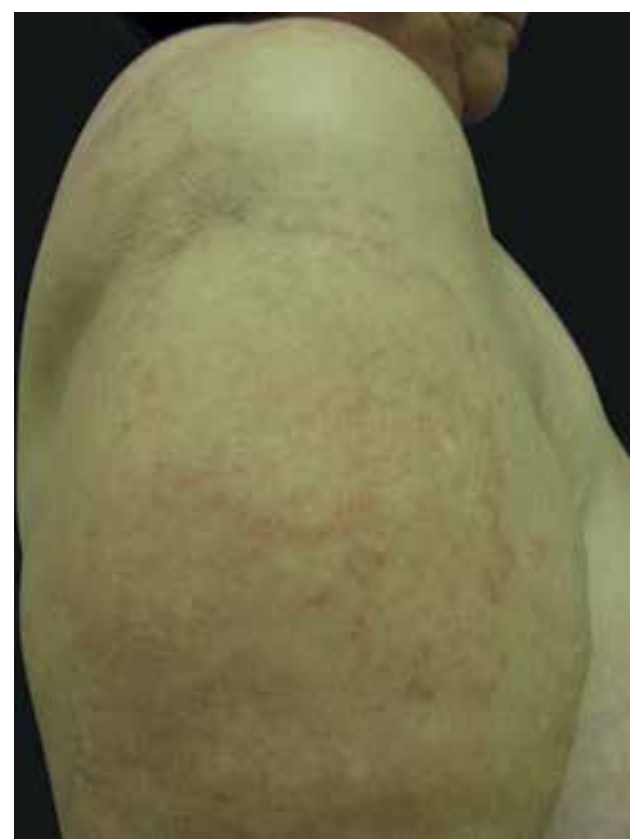

FIGURE 3: Erythematous plaques with an annular configuration on the arm

GA frequently resolves spontaneously in two years, many times after a biopsy, and usually does not leave any atrophic sequelae. ${ }^{2,3}$ Gunes et al. described that the damage to the elastic fibers is one of the main features of GA and it can originate from delayed-type hypersensitivity. Thus, the destruction of elastic fibers may be intrinsic to GA, being strong enough to cause visible cutaneous atrophy such as anetoderma. ${ }^{4}$

Treatment can be topical, with tacrolimus, pimecrolimus, imiquimod, steroid, cryotherapy and phototherapy. It can be intralesional, with interferon and steroid or systemic, with antimalarials, retinoids, steroids, ciclosporine, dapsone, infliximab, etanercept e efalizumab. ${ }^{2,5}$ Treatment with rifampicin, ofloxacine and minocycline was described with good response., ${ }^{5,6}$ Disseminated GA usually presents with a prolonged clinical course, difficult to be treated.

Phototherapy is the exposure to ultraviolet radiation for therapeutic purposes and can be done using natural light, ultraviolet $A$ (UVA) or ultraviolet B (UVB). Controlled and repeated exposures to ultraviolet light are used, in order to change the cutaneous pathophysiology and induce regression or control of progression of dermatoses. Both UVA and UVB are capable of altering cellular DNA. ${ }^{7}$

The mechanism of action of phototherapy in GA is still uncertain but is apparently associated to the inhibition of $\mathrm{T}$ lymphocytes and the resulting effects on the macrophage and metalloproteinases production. ${ }^{2}$ It is believed to be a delayed-type hypersensitivity mechanism in the pathogenesis of GA against unknown antigens in the skin. ${ }^{8}$

In the literature, there are two reports of GA treated with narrowband UVB. The first one was in 2005, with remission after 24 weekly sessions and no recurrence after six months of follow-up. ${ }^{9}$ The second was in 2015 after 27 sessions, three times a week, with maintained remission after one year of follow-up. ${ }^{10}$ In this case, the 

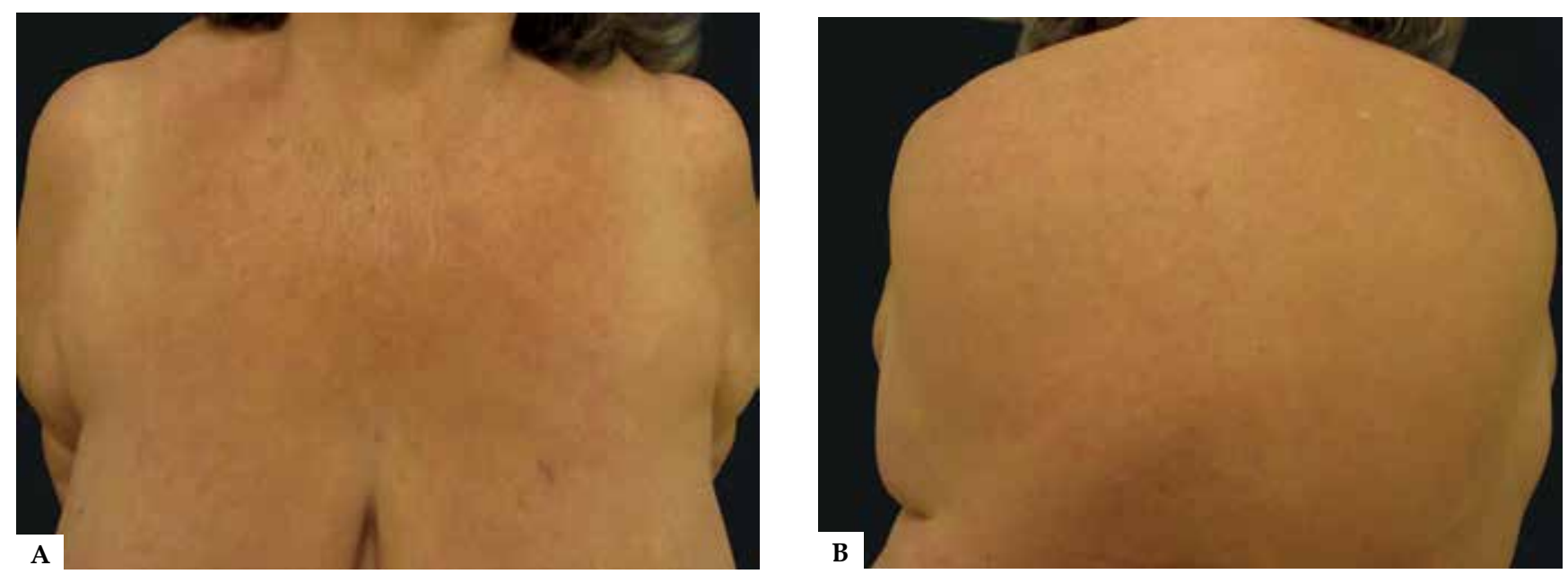

FIGURE 4: A and B. Post-treatment with narrowband UVB phototherapy

number of sessions was higher, also with satisfactory results, with quick and complete regression of the condition and no recurrence after two years of follow-up.

The objective of this case report was to illustrate a case of disseminated GA refractory to treatment due to the patient's comorbid- ities, since the use of steroids was limited by diabetes mellitus and sulfone had to be discontinued due to hematuria. We must highlight the favorable result after narrowband UVB phototherapy, making it a good therapeutic option with few side effects and contraindications, appropriate for patients with multiple comorbidities. $\square$

\section{REFERENCES}

1. $\mathrm{Na} \mathrm{CH}$, Kim MS, Song SH, Shin BS. Solitary granuloma annulare: The first case of development on a healthy child's palm. Ann Dermatol. 2014;26:113-4.

2. Browne F, Turner D, Goulden V. Psoralen and ultraviolet A in the treatment of granuloma annulare. Photodermatol Photoimmunol Photomed. 2011;27:81-4.

3. Watanabe S, Tanaka M, Kobayashi K, Sawada M, Ishizaki S, Tsurui K, et. al. Remission of generalized erythematous granuloma annulare after improvement of hyperlipidemia and review of the Japanese literature. Dermatol Pract Concept. 2014:4:97-100

4. Güneş P, Göktay F, Mansur AT, Köker F, Erfan G. Collagen elastic tissue changes and vascular involvment in granuloma annulare: a review of 35 cases. J Cutan Pathol. 2009;36:838-44

5. Garg S, Baveja S. Generalized granuloma annulare treated with monthly rifampicin, ofloxacin, and minocycline combination therapy. Indian J Dermatol. 2013;58:197-

6. Marcus DV, Mahmoud BH, Hamzavi IH. Granuloma annular treated with rifampicin ofloxacin and minocycline combination therapy. Arch Dermatol. 2009;145:787-9.

7. Muchenberger S, Schöpf E, Simon JC. Phototherapy with UV-A-I for generalized granuloma annulare. Arch Dermatol. 1997;133:1605.

8. Antoniorondonlugo.com [Internet]. Santamaria JR, Deonizio JD. Fototerapia - indicações não usuais. [acesso 14 dez 2014. Disponível em: http:// antoniorondonlugo.com/blog/wp-content/uploads/2010/05/77-Fototerapiaindicaciones-no-usuales.1.pdf
9. Inui S, Nishida $Y$, Itami S, Katayama I. Disseminated granuloma annulare responsive to narrowband ultraviolet B therapy. J Am Acad Dermatol. 2005;53:533-4.

10. Solano-López G, Concha-Garzón MJ, de Argila D, Daudén E. Successful Treatment of Disseminated Granuloma Annulare with narrowband UV-B Phototherapy. Actas Dermosifiliogr. $2015 ; 106: 240-1$

\footnotetext{
CORRESPONDENCE ADDRESS:

Bianca Pinheiro Bousquet Muylaert

R. Enéas de Siqueira Neto, 340

$J d$. das Imbuias

04829-300 São Paulo, SP

Brazil

E-mail:biamuylaert@hotmail.com
}

How to cite this article: Muylaert BPB, Almada R, Vasconcelos RCF. Granuloma annulare treated with narrowband UVB phototherapy. An Bras Dermatol. 2017;92(5 Suppl 1):82-4. 